\title{
Research on the Influence of Sensor Network Communication in the Electromagnetic Environment of Smart Grid
}

\author{
Yiying Zhang, ${ }^{1}$ Suxiang Zhang, ${ }^{2}$ and Yuemin Ding ${ }^{3}$ \\ ${ }^{1}$ College of Computer Science and Information Engineering, Tianjin University of Science \& Technology, Tianjin 300222, China \\ ${ }^{2}$ State Grid Information \& Telecommunication Branch, Beijing 100761, China \\ ${ }^{3}$ Tianjin University of Technology, Tianjin 300222, China
}

Correspondence should be addressed to Yiying Zhang; winzyy@163.com

Received 8 November 2015; Accepted 5 January 2016

Academic Editor: Hui Cheng

Copyright (C) 2016 Yiying Zhang et al. This is an open access article distributed under the Creative Commons Attribution License, which permits unrestricted use, distribution, and reproduction in any medium, provided the original work is properly cited.

\begin{abstract}
Smart grid adopts wildly various sensors for lots of applications to sense work environment, monitor production process and realize the automation control, and so forth. However, due to the wireless and open communication, the electromagnetic phenomena in the communication and the electric network of the sensor network usually produce the mutual interference. Meanwhile, electrical equipment and sensors are usually in high pressure electromagnetic environment. Therefore, it is very necessary and important to ensure the reliability and stability in smart grid applications. And the sensing and communication device must be after equal parameter simulation environment under strict evaluation and verification can be put to use in actual production operation system. In this paper, we analyze the application of wireless sensor network in smart grid and propose the test method of the interaction between WSN and smart grid.
\end{abstract}

\section{Introduction}

Smart grid adopts wildly various sensors for lots of applications to sense work environment, monitor production process and realize the automation control, and so forth, such as to comprehensively sense (monitor) the specific objects, and collects the useful data and controls devices $[1,2]$. Sensor networks can be applied to many aspects: the remote meter information acquisition, line fault location, and line tower and power equipment real-time monitoring and early warning, effectively monitoring the running state of power system, improving the efficiency of power system. Therefore, the wireless sensor networks become a useful supplement to the production, transmission, distribution, and consumption link power. Sensor networks can obtain the running state of power grid and parameter information and provide more comprehensive and complete operation data of power grid for power grid operation and management, which is beneficial to the decision system control implementation scheme and plans to deal with has become an effective component of smart grid.
Figure 1 describes the network architecture of sensor network in the whole production process of the smart grid. Usually, the terminal equipment, such as sensors and intelligent device, plays an important role for information acquisition and collection, data fusion processing, and transmission function of the smart grid $[1,3]$. In view of the smart distribution link, sensor network is mainly used in sensor networks system in various applications, such as the intelligent home appliances, intelligent home system [2, 4], wireless security system, user electric energy data acquisition system, the main hardware equipment including intelligent terminal interaction, intelligent interactive set-top boxes, and smart socket.

However, due to the wireless and open communication, the electromagnetic phenomena in the communication and the electric network of the sensor network usually produce the mutual interference. Moreover, the electrical equipment and sensors are usually in high pressure electromagnetic environment $[5,6]$. It is very important to ensure the reliability and stability in smart grid applications. Therefore, sensing and communication device must be after equal 


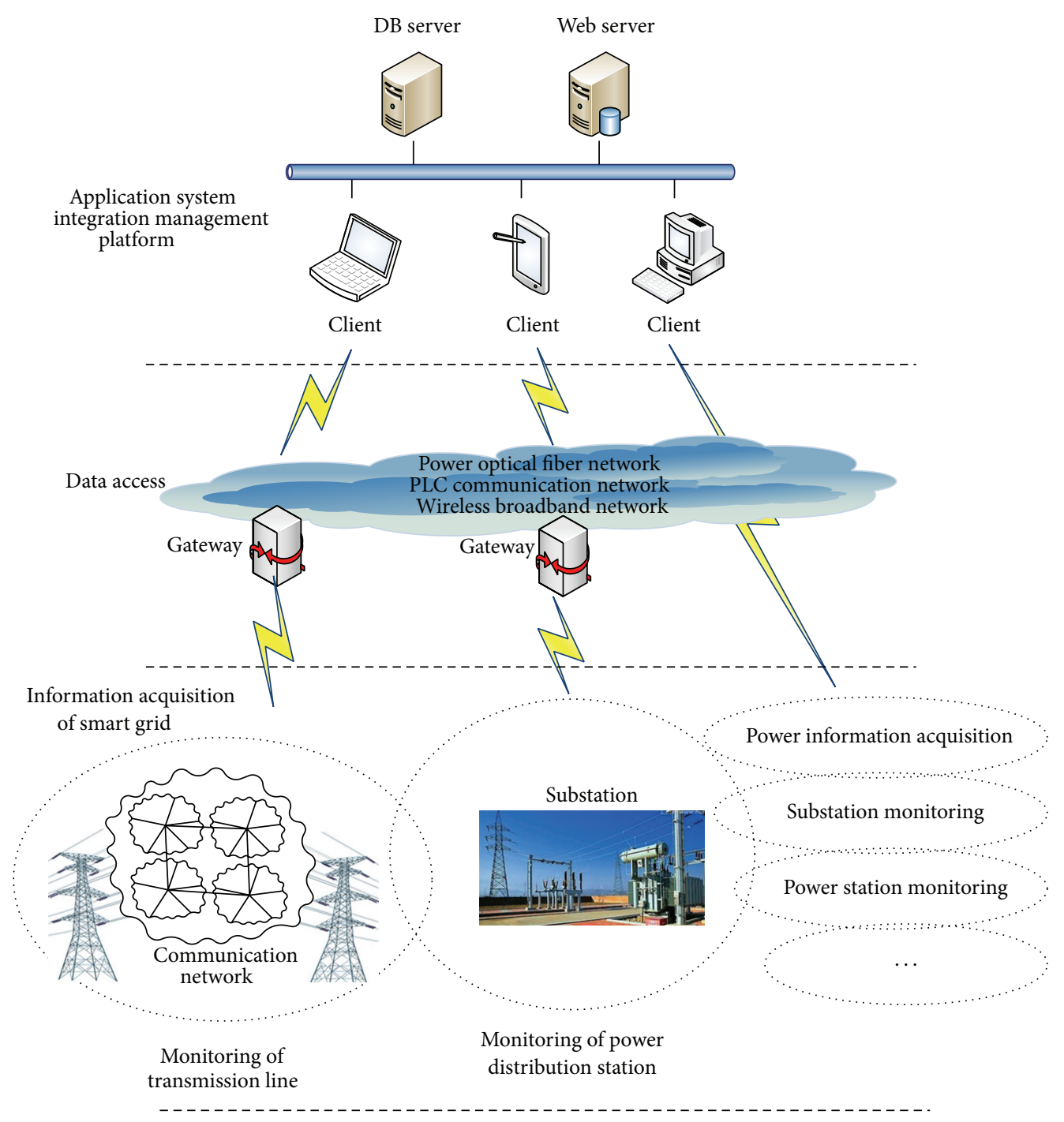

FIGURE 1: The architecture of sensor network for production process in smart grid.

parameter simulation environment under strict evaluation and verification can be put to use in actual production operation system.

For the effect research of wireless sensor network in smart grid [7], we need build assessment verification environment and simulate different levels electromagnetic parameters of the power distribution, transmission, and other grid operations. And then, we can start the effect test. The test content includes the interaction of the sensor network and network transmission equipment, distribution network, and the mutual influence of electric equipment, and the sensor network and electrical equipment influence each other [6-9].

The test is mainly through electromagnetic compatibility test method of transmission line in distribution network to analyze whether there are electrical characteristics of sensor network and through the electromagnetic compatibility of the test method of sensor networks to confirm whether there are electrical equipment network characteristics of comparative analysis [10]. Therefore, we mainly focus on the network characteristics, electrical characteristics, and electromagnetic compatibility.

The rest of this paper is organized as follows. In Section 2, we introduce applications of various links in the smart grid, such as power generation, transmission, power generation, distribution, and power. In Section 3, we introduce the effect of sensor network in smart grid, and then, in Section 4, we give the conclusion.

\section{Applications in Smart Grid}

Sensors network supports terminals or systems in smart grid, which can keep two-way information exchange, monitoring, control, and maintenance in real time. Customers will interact extensively with the network, both in providing power consumption data and even in feeding back domestically produced energy into the grid. Metering will no longer be electromechanical, but rather digital, which will enable 
real-time pricing and net metering [1-3]. Adopting sensor network, smart grid improves the intelligent abilities in sensing, inspection, communication, IT, energy and new material technology, and so on. The basic and key technology in the smart grid is the advanced micro-sensor networks and communication technology $[1,2]$.

2.1. WSN in the Power Generation. In the power generation, sensors are mainly used to sense the power generation devices or environment. Generators are key equipment in the power plants; thus it is very important to ensure their safety and stability $[7,11]$. Normally, we monitor states of generators by sensors, such as the various sensors, balance sensors, smoke sensors, and magnetic field strength sensors. According to the data from sensors, we can know the detailed state of the generators and environment and then do the fault diagnosis, early warning, optimal scheduling, and so forth.

2.2. WSN in the Power Transmission. The transmission line is responsible for delivering the power resources to substations, user-side, and so forth; it is necessary to monitor and protect the transmission line. Because accidents occurred such as the coal mining, construction, and other external damage, the transmission line faces a significant threat to the safe operation of the grid [2,5]. Moreover, there are large numbers of power towers in more broad scope, and relying on the daily inspection of the transmission line patrol officers, it is difficult to achieve timely and accurate discovery of fault occurring $[8,11]$.

For the tower, we usually deploy the front-end monitoring devices using high-precision dual-axis tilt sensor and microelectronic control technology design. The dual-axis tilt sensor on the tower in the smooth lines and the crossline direction of the inclination of real-time measurement through the program by a microprocessor instruction set. Inclination data of the dual-axis tilt sensors is used to monitor the use of transparent transmission mode and communicate with server through the RS232 serial interface with a microprocessor as shown in Figure 2.

2.3. WSN in the Power Substation. Substation automation is a critical role in power systems. As key building blocks of smart grid, smart substations combine the power grid management with the communication management $[12,13]$. In smart substations, we deploy types of sensing devices to sense the objects and monitor the devices, such as $\mathrm{SF}_{6}$, temperature, and humidity, as shown in Figure 3.

2.4. WSN in the Power Distribution. In the power distribution, most supply companies mostly adopt the scheduling acquisition and supervisory control (SCADA) systems to manage the distribution system. Nowadays, they start the new support system based on IEC 61968/61970/61850. In order to collect the information real-timely and accurately, we need deploy many sensors to detect or sense the objects in distribution system, such as the current and voltage sensing, fiber optic temperature sensing, and power grid interface detection.
2.5. WSN in the Power Consumption. WSNs are widely utilized in user-side application and support many new functions, such as the smart home, electric vehicle (EV), Advanced Metering Infrastructure (AMI), and power grid emergency management (as shown in Figure 4). In order to achieve convenient management, smart grid starts to adopt the three-dimensional visualization display for the full range of detection. Data visualization is a graphical representation of data in a format that allows a qualitative understanding of the information provided as shown in Figure $4[12,14]$.

Moreover, WSNs also are utilized for smart grid emergency information management which is an important application for the grid environment monitoring, grid operation states real-time sensing and multidimension visualization, and integrated services as shown in Figure 5. According to the above requirements, we deploy the technology of WSN in the applications on power grid online monitoring, intelligent supervisory control, inspection, and other aspects. In [15], the authors present a testbed based on ZigBee for centralized monitoring server operated to collect periodically all data of the electricity consumption and generation and to control the amount of electricity consumption and charge; the testbed provides valuable insights into design decisions of a smart grid using wireless sensor networks.

\section{Test Process and Effect Analysis in Smart Grid}

3.1. Test Process and Effect Analysis in Transmission Equipment on Sensor Network. In the transmission line, the corona, electrical discharge, electric flashover, arc, and so forth usually cause the radio interference wave. However, the probability of flashover and arc is very little, which are mainly instantaneous and local, and can be neglected in general [16]. A transmission line under reasonable design and construction will not produce sparks discharge. Therefore, the source of radio interference in the transmission line is mainly generated by the corona wire and the insulator strings, and corona is interference of the main ingredients.

To test the transmission line environment, it is necessary to establish a typical distribution environment for evaluation of the complete set of distribution and intelligent power environments composed of smart meters, smart appliances, intelligent interactive terminal, the use of electric information acquisition system, and a variety of sensor terminal and communication devices. Based on the simulation of typical distribution network, we can test system stability, system security, technical feasibility, system performance, and electrical performance parameters for multisensors terminal, multicollection module, gateway, multicommunication, multibusyness, and so forth.

As shown in Figure 5, the distribution power network composed of the artificial mains network (AMN) [17], power cables, the base unit, the switch control module, the noise generating device, and so forth and the device $(0-\mathrm{N})$ are EUT (equipment under test); $\mathrm{K}$ is the control module of switch; a denotes attenuator/noise signal from noise generator/wireless sensor network module/collection/PLC terminal and so forth. Through the smart grid distribution/electric 


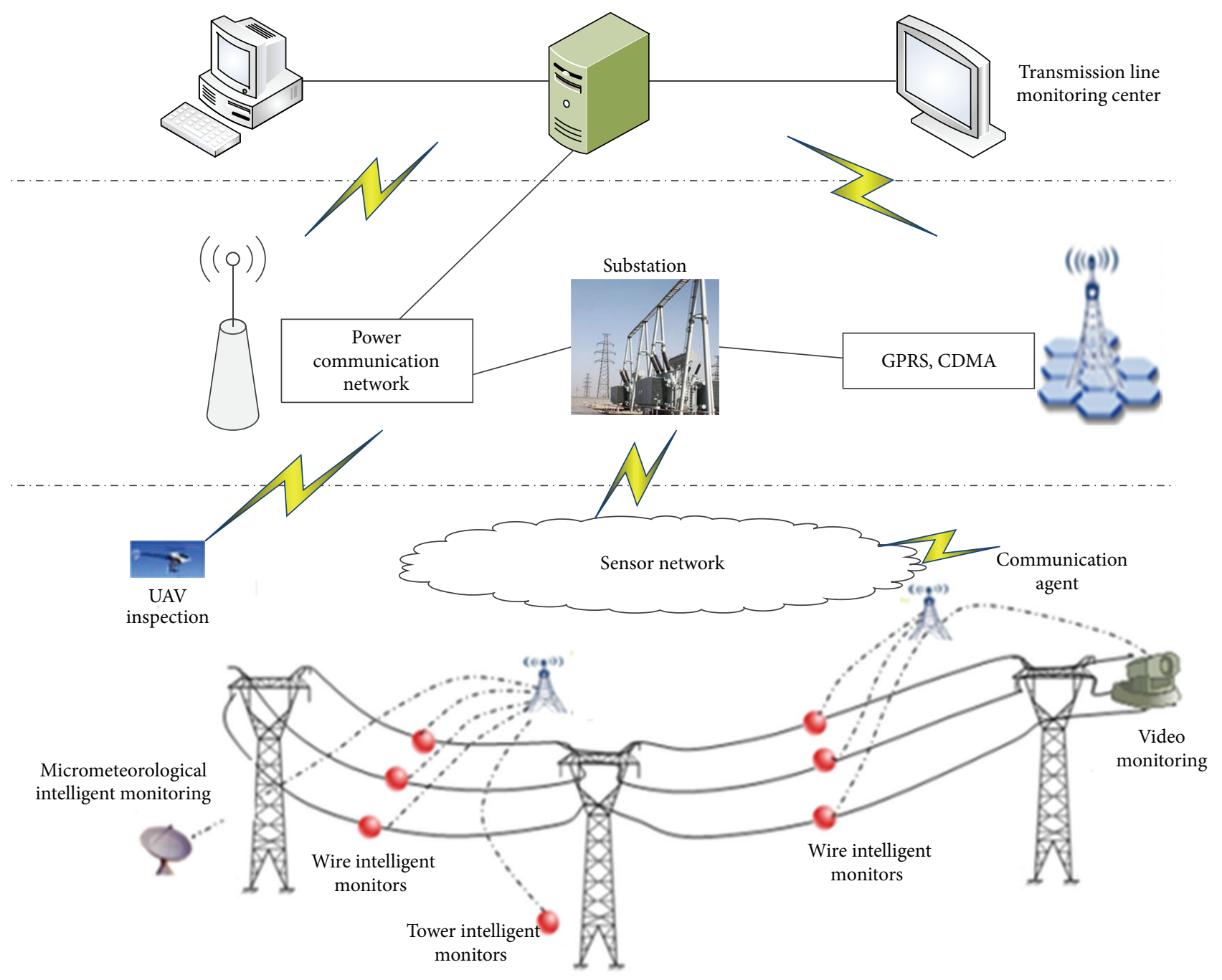

FIGURE 2: Sensors monitoring system for the transmission line.

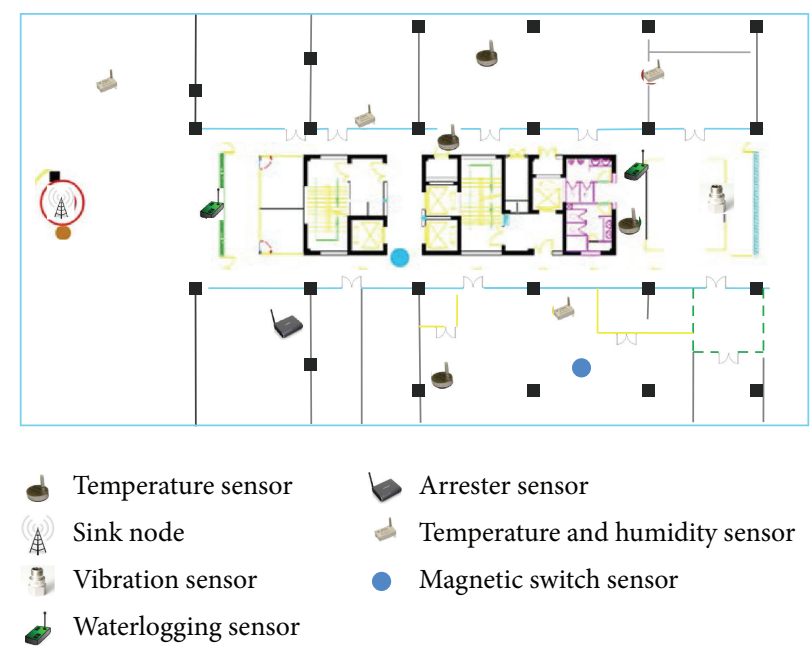

FIGURE 3: Sensor network in the substation. 


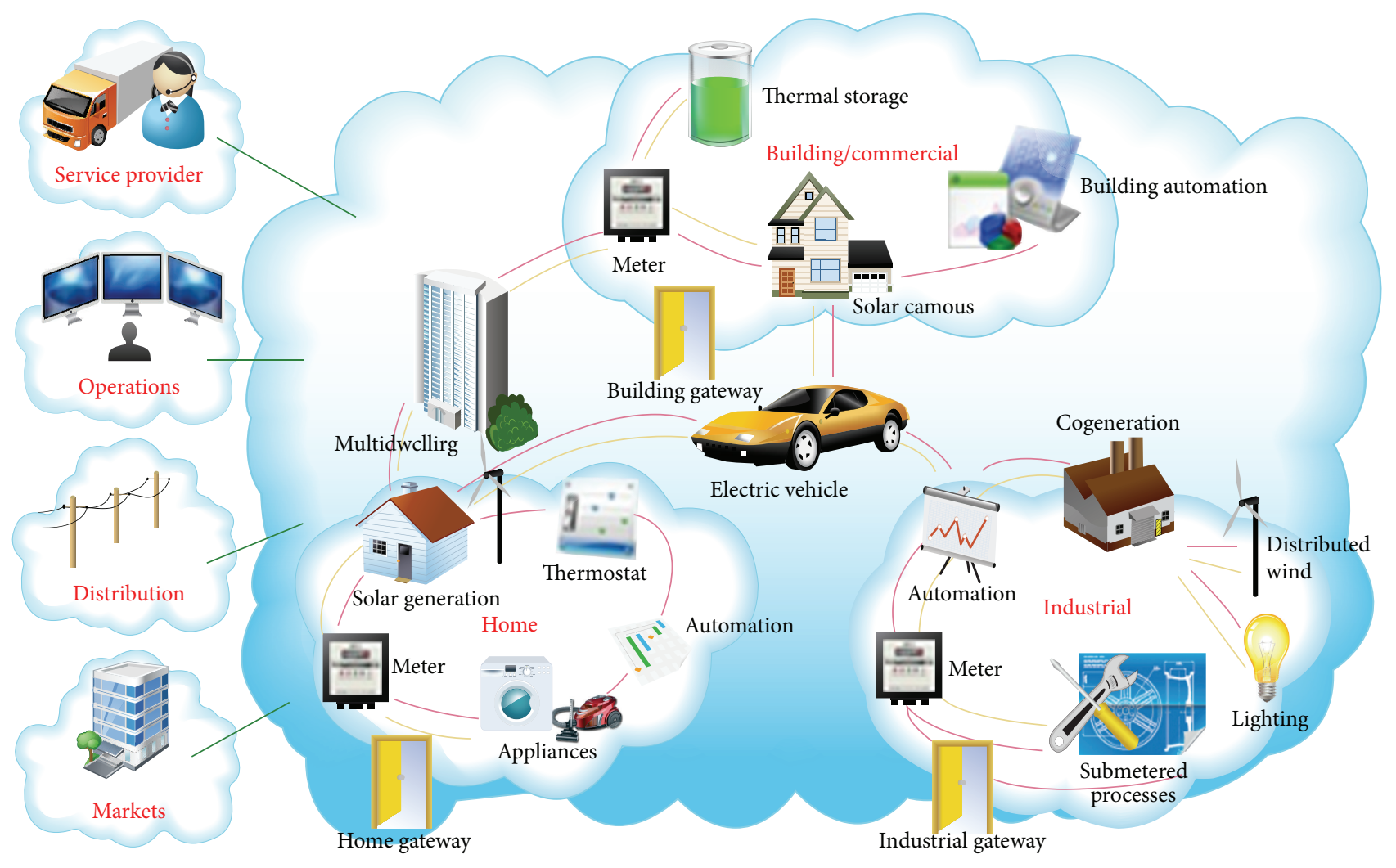

FIgURE 4: Applications in smart grid.

test network, we can simulate the real aircraft equipped with grid structure. In accordance with the actual measured distribution network or test network configuration utility grid topology and line conditions, the access test results of the test network can provide true and accurate reference for the sensor network.

To test the effect of sensor network in transmission equipment, we design a test system based on the high-speed data processing capability of DSP (Digital Signal Processing). First, we utilize the three-phase AC voltage acquisition module and the amount of current high-speed acquisition to adjust the voltage and current levels down to a reasonable range and then converter chip into the DSP (TMS320F2812) processor by the A/D for high-speed operation processing.

Core algorithm uses the classic FFT algorithm, after a series of quick speed, high-precision computing and data processing operations coming to the following values: threephase voltage and current valid value; three-phase fundamental voltage and current valid value; three-phase fundamental active power, reactive power, and power factor; voltage and current harmonics 2 to 64 and harmonic distortion. The detection principle block diagram is shown as Figure 6.

Usually, we just only consider the magnetic field of space line for the accurate calculation of the magnetic field. According to the superposition principle [18], three phase currents $I_{A}, I_{B}$, and $I_{C}$ phase wires in the horizontal and vertical components of the magnetic flux density at $P$ are as follows:

$$
\begin{aligned}
B_{P x} & =\sum_{i=1}^{6} B_{i x}=\frac{\mu_{0} I}{2 \pi} \sum \frac{y_{i}-y}{r_{i}^{2}} \cos \varphi_{i}, \\
B_{P y} & =\sum_{i=1}^{6} B_{i y}=\frac{\mu_{0} I}{2 \pi} \sum \frac{x_{i}-x}{r_{i}^{2}} \sin \varphi_{i} \\
B_{P} & =\sqrt{B_{P x}^{2}+B_{P y}^{2}}, \\
r_{i} & =\sqrt{\left(x_{i}-x\right)^{2}+\left(y_{i}-y\right)^{2}}
\end{aligned}
$$

where $x_{i}, y_{i}$ are horizontal and vertical coordinates; $x, y$ are horizontal and vertical coordinates of $P$; $r_{i}$ denotes the distance from $P$ to the line.

The test process is as follows:

(a) Deploy 27 test points, and the measuring instrument is EFA-200 electromagnetic analyzer.

(b) According to (1), we can get Tables 1 and 2, which show the part of test results for current electromagnetic status and analogy. And parameters of electromagnetic field strength are $0.146 \mathrm{kV} / \mathrm{m}\left(E_{\max }\right)$, $2.81 \mathrm{~T}\left(B_{\max }\right)$, which are in the range of limitation $(E$ : $4 \mathrm{kV} / \mathrm{m}, B: 0.1 \mathrm{mT})$. 


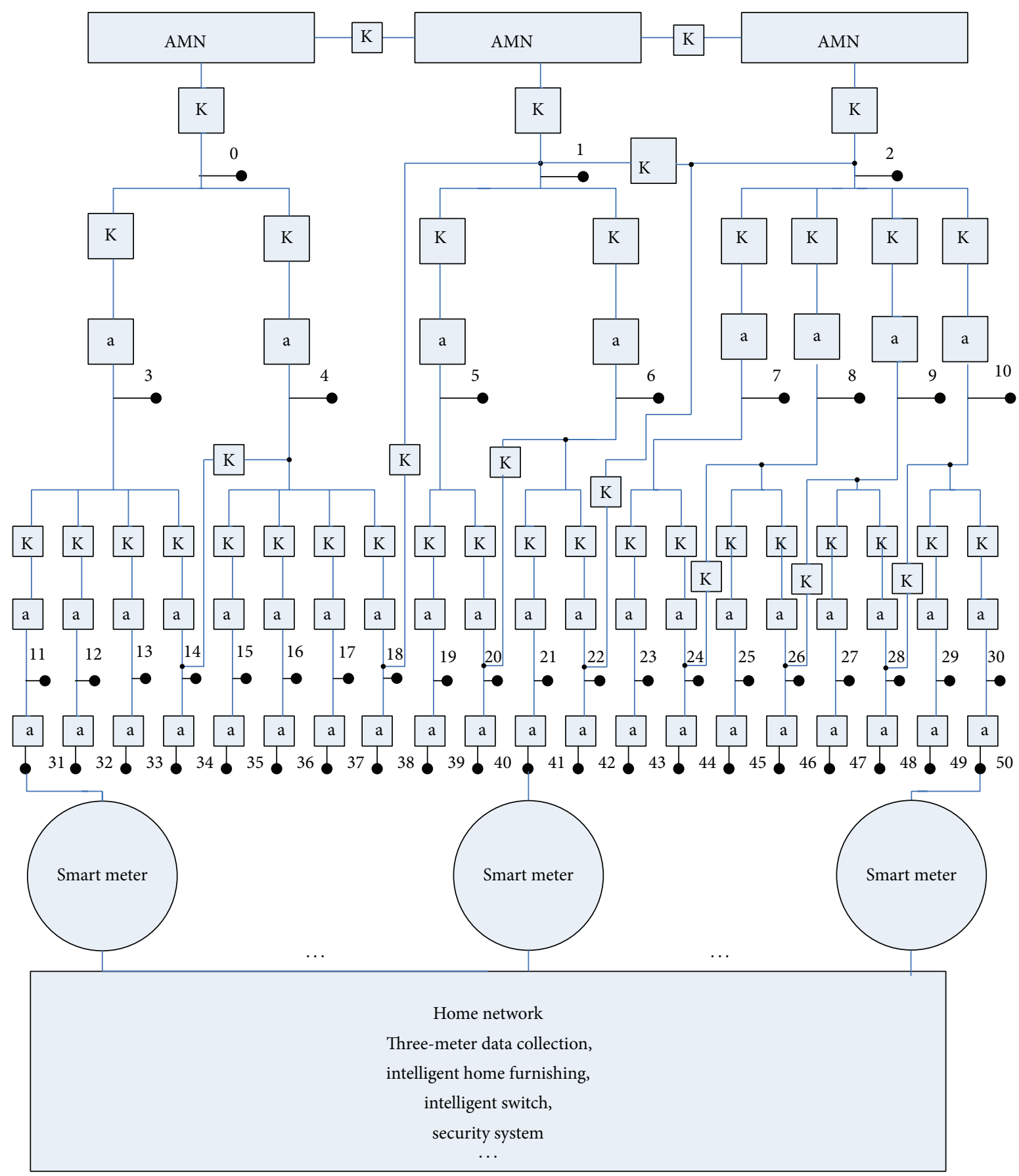

FIGURE 5: The distribution power simulation architecture in smart grid.

We adopt the same electric field and the magnetic field to test as shown in Figures 7 and 8. They almost have the substantial variation. The vertical component of all there was a low point; the horizontal component is reduced after the first increase, and the highest point occurs around $8 \mathrm{~m}$. Theoretical calculations and actual measurements are similar. However, they are not the same; it is due to the current value of the high-voltage transmission lines with electricity load changes. Therefore, the magnetic flux density is measured with a series of changes in electricity load instability value, and the calculation and testing are not exact. This also shows that the trend of either $10 \mathrm{kV}$ or $35 \mathrm{kV}$ magnetic induction intensity map is the same but of slightly different value. The synthetic magnetic flux density is determined by the horizontal and vertical components.

3.2. Effect of Substation Equipment on Sensor Network. The influence of sensor network in the power distribution network includes two parts: the electromagnetic radiation interference and the corona radiation interference. The 


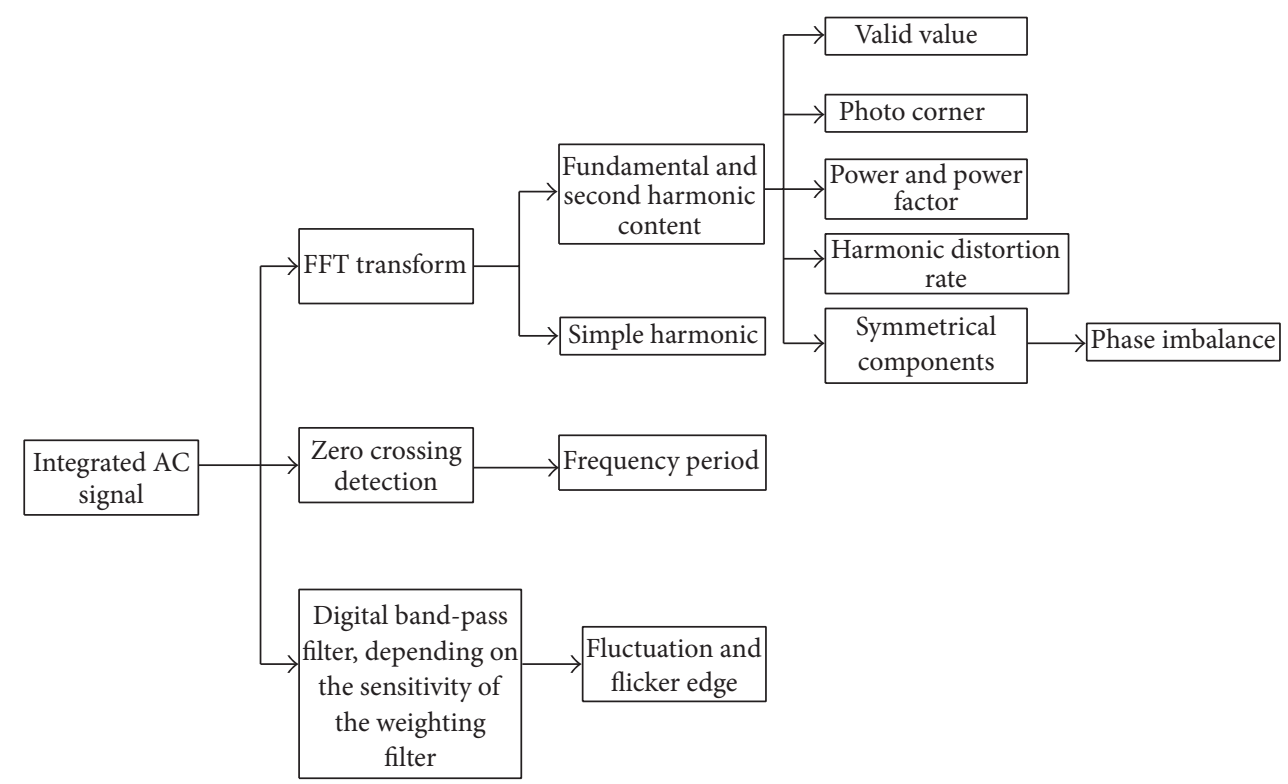

FIgURE 6: The detection principle block diagram.

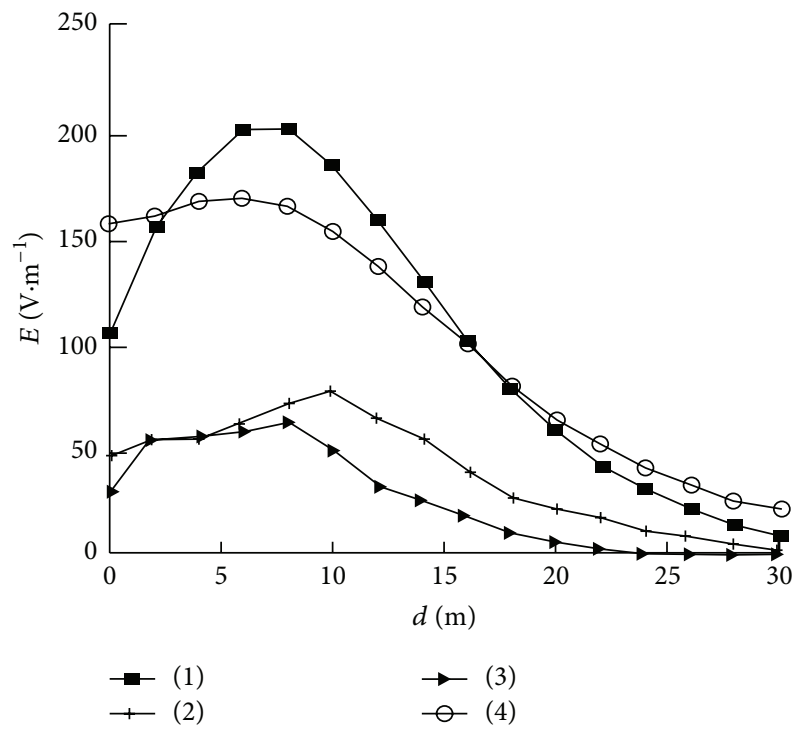

Figure 7: The measured electric field strength.

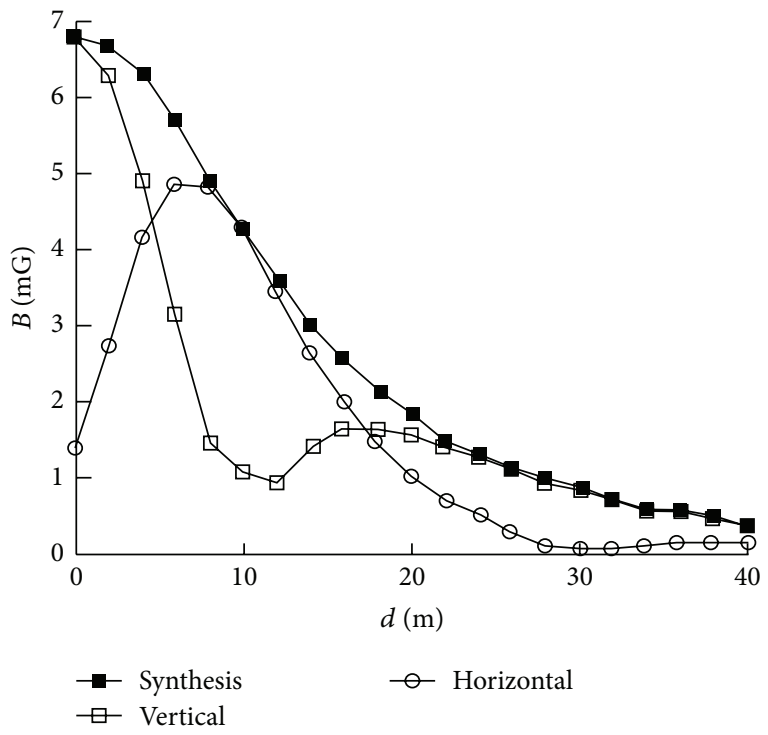

Figure 8: The measured magnetic field strength. electromagnetic radiation is a form of electromagnetic wave through the space of energy flow and is limited to nonionizing radiation. The electromagnetic radiation (mainly $50 / 60 \mathrm{~Hz}$ low frequency, which is different from the high frequency electromagnetic wave) in the power system mainly indicates the high-voltage power equipment in the substation. There is a certain potential difference between the electric power equipment and the earth, which forms a strong power frequency $(50 \mathrm{~Hz})$ electromagnetic field.

To build the distribution network simulation environment, we should simulate variable part of electromagnetic interference generated by the above-mentioned phenomena. And, in the test architecture, we tested the following objects: various sensors, electromagnetic interference of the wireless communications device, the bit error rate testing, error change of the frame rate, assessing CRC convolutional codes, FEC of the effectiveness of the error control before, ARQ automatic retransmission, and so forth in such interference checking mechanism to assess the sensor network equipment and power distribution equipment, electromagnetic compatibility, and security control device.

In the distribution network substation segment, due to the different specific application scenarios, the specific sensor networks deployed position is not the same as in the distribution network transmission link, and we usually adopt the multihop chain topology; and in the distribution network 


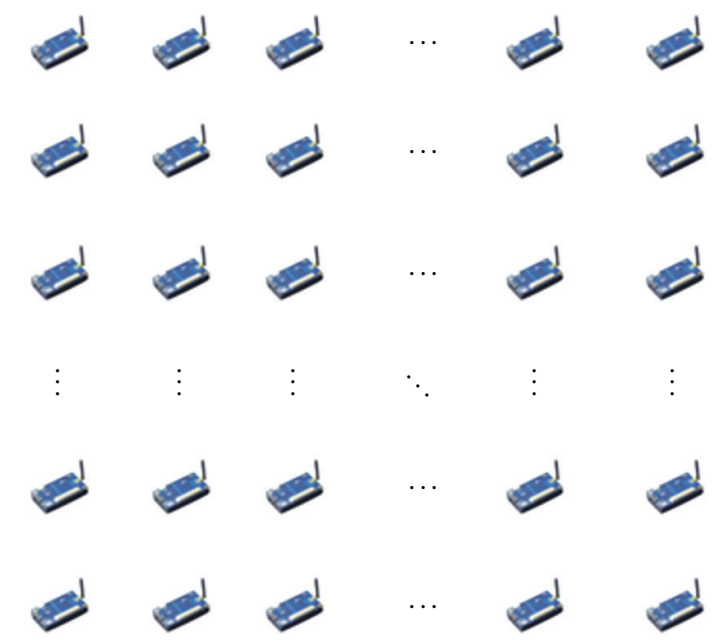

FIGURE 9: The simulation environment of sensor network.

TABLE 1: Electromagnetic radiation measurements environmental status.

\begin{tabular}{lccc}
\hline Point & $E /\left(\mathrm{kV} \cdot \mathrm{m}^{-1}\right)$ & $B / \mathrm{mT}$ & Remark \\
\hline Y1 & 0.002 & $4.35 \times 10^{-5}$ & Near school \\
Y4 & 0.043 & $1.27 \times 10^{-4}$ & Near wall \\
Y5 & 0.106 & $2.32 \times 10^{-4}$ & Near high-tension line \\
Y7 & 0.113 & $3.08 \times 10^{-4}$ & Near high-tension line \\
Y9 & 0.110 & $2.97 \times 10^{-4}$ & Near road \\
Y10 & 0.118 & $4.0 \times 10^{-4}$ & Near road \\
Y12 & 0.16 & $2.19 \times 10^{-3}$ & Near road \\
Y13 & 0.125 & $8.74 \times 10^{-4}$ & Near road \\
Y14 & 0.102 & $2.28 \times 10^{-4}$ & Near road \\
Y15 & 0.06 & $1.67 \times 10^{-4}$ & Near road \\
Y22 & 0.02 & $1.36 \times 10^{-4}$ & Near cross \\
Y27 & 0.008 & $1.18 \times 10^{-4}$ & In school \\
\hline
\end{tabular}

TABLE 2: Electromagnetic radiation measurements analogy.

\begin{tabular}{lccc}
\hline Point & $E /\left(\mathrm{kV} \cdot \mathrm{m}^{-1}\right)$ & $B / \mathrm{mT}^{\mathrm{T}}$ & Remark \\
\hline 1.1 & 0.114 & $2.26 \times 10^{-4}$ & Near high-tension line \\
1.2 & 0.105 & $1.86 \times 10^{-4}$ & Near high-tension line \\
1.4 & 0.013 & $1.04 \times 10^{-4}$ & \\
1.5 & 0.002 & $8.21 \times 10^{-5}$ & \\
1.9 & 0.003 & $9.13 \times 10^{-5}$ & \\
1.10 & 0.004 & $1.03 \times 10^{-4}$ & Ground \\
1.19 & 0.003 & $2.27 \times 10^{-4}$ & $1.0 \mathrm{~m}$ height \\
1.21 & 0.002 & $9.35 \times 10^{-5}$ & \\
\hline
\end{tabular}

substation session, we generally employ the complex mesh topology. However, to build a distribution network simulation scenario for the application of the network environment, we should have some flexibility to achieve variability based on changes in topology scenarios, adaptability. Also, the scene switches are required to be quick and easy for a uniform standard network simulation environment and to adapt to different application scenarios $[19,20]$. The project intends to build a sensor network simulation environment shown in Figure 9.

In Figure 9, there are 225 sensors (composition lattice of $15 \times 15$ ). These nodes are unified addressing node and supplied with battery or DC power. If we test the network connectivity, functional or performance, we adopt the DC power supply; otherwise, if we test the network node energy consumption and endurance testing, we adopt the battery power supply. And we can test whether a node is in the system by the controlled route via a wired or wireless manner. Unattended node does not affect other nodes in testing. And Figure 10 shows the deployment of sensors in real environment.

Usually, the corona radiation mainly includes the following two aspects. (1) Because the high-voltage electrical equipment potential gradient is relatively large, it will produce corona of the surrounding air discharge. Therefore, it will produce corona, especially in the early stage of the new power distribution station. After a period of time, the trend becomes weakened and stable. The form of discharge is a few $10 \mathrm{kHz}$ of impulse electromagnetic noise, the frequency range of the frequency harmonic is not wide, and the frequency is lower than that of the GB8702-88 (electromagnetic radiation protection regulations). (2) Normally, the operation of the power distribution station produced the electromagnetic radiation interference cause of corona. Distribution station may produce electromagnetic radiated noise (radio interference). The spectrum can be as high as a few $100 \mathrm{MHz}$, but this kind of discharge is not the main reason for interference.

To research the effect of sensor network in power distribution [21], we test the environmental frequency electromagnetic field in $35 \mathrm{kV}$ and $10 \mathrm{kV}$ power stations. The research range includes the range from the station to $100 \mathrm{~m}$, the wall of power station, and the sensitive targets near residents. The height measured is at $1.5 \mathrm{~m}$, and we test the frequency electric field intensity, frequency magnetic strength, and the weather conditions are without rain, fog, or snow.

Tables 3 and 4 show that the test frequency electromagnetic field results of indoor type in the power distribution 
TABLE 3: The test result in $35 \mathrm{kV}$ power station (frequency electromagnetic field in outdoor type).

\begin{tabular}{lccc}
\hline Point & Measuring position & $\begin{array}{c}\text { Outdoor type (overhead line) } \\
\text { Electric field strength } / \mathrm{kV} \cdot \mathrm{m}^{-1}\end{array}$ & Magnetic strength/mT \\
\hline 1 & East side & $2.75 \times 10^{-2}$ & $8.68 \times 10^{-5}$ \\
2 & South side & $7.53 \times 10^{-1}$ & $1.86 \times 10^{-3}$ \\
3 & West side & $9.04 \times 10^{-1}$ & $6.42 \times 10^{-4}$ \\
4 & North side & 1.33 & $5.70 \times 10^{-4}$ \\
5 & Sensitive point & $9.04 \times 10^{-1}$ & $6.72 \times 10^{-4}$ \\
\hline
\end{tabular}

TABLe 4: The test result in $35 \mathrm{kV}$ power station (frequency electromagnetic field in indoor type).

\begin{tabular}{lccc}
\hline Point & Measuring position & $\begin{array}{c}\text { Indoor type (cable entry) } \\
\text { Electric field strength } / \mathrm{kV} \cdot \mathrm{m}^{-1}\end{array}$ & Magnetic strength $/ \mathrm{mT}$ \\
\hline 1 & East side & $<1.00 \times 10^{-3}$ & $2.45 \times 10^{-5}$ \\
2 & South side & $2.08 \times 10^{-3}$ & $2.75 \times 10^{-5}$ \\
3 & West side & $2.67 \times 10^{-3}$ & $1.04 \times 10^{-4}$ \\
4 & North side & $3.22 \times 10^{-3}$ & $2.42 \times 10^{-5}$ \\
5 & Sensitive point & $3.42 \times 10^{-3}$ & $2.04 \times 10^{-5}$ \\
\hline
\end{tabular}

station (technology) are lower than the outdoor type. By the test frequency electromagnetic field results in $35 \mathrm{kV}$ and $10 \mathrm{kV}$ power station, the electric field range in $35 \mathrm{kV}$ power station is about $1.27 \times 10^{-2} \sim-1.33 \mathrm{kV} / \mathrm{m}$; the induction intensity range is about $2.78 \times 10^{-5} \sim 1.86 \times 10^{-3} \mathrm{mT}$; indoor-type electric field strength is about $1.00 \times 10^{-3} \sim 3.22 \times 10^{-3} \mathrm{kV} / \mathrm{m}$; the magnetic strength range is about $2.42 \times 10^{-5} \sim 9.89 \times 10^{-4} \mathrm{mT}$. In the $10 \mathrm{kV}$ power station, the outdoor electromagnetic strength is $1.31 \times 10^{-3} \sim 0.576 \mathrm{kV} / \mathrm{m}$; magnetic strength range is $6.45 \times$ $10^{-5} \sim 3.32 \times 10^{-4} \mathrm{mT}$; indoor electric field strength is $1.00 \times$ $10^{-3} \sim 0.0125 \mathrm{kV} / \mathrm{m}$; the magnetic strength is $1.57 \times 10^{-5} \sim 9.34$ $\times 10^{-4} \mathrm{mT}$.

The internal circuit breakers, disconnectors, and other primary devices in the substation will generate the arc, when we do the switching operation or switch fault current, due to the presence of inductive load. When the switch contact is broken, the resulting arc extinguishing or renewed would cause a plurality of frequency components attenuated oscillations, which can be sent to the surrounding space through the connection between the bus and device transient electromagnetic radiation to form the electromagnetic field radiation. Also, the equipment operating interference is mainly caused by the gap breakdown $\mathrm{SF}_{6}$ and vacuum gap breakdown radiation signal generated [22] as shown in Figure 11.

3.3. Construction of Network Simulation Environment for the Use of Electricity. In the simulation environment, the intelligent electrical verification environment should contain fiber composite low voltage cable, power line carrier, micro power wireless, wireless public network, and so forth. And, the environment also can provide the safe, stable, and reliable operation of the information transmission channel and technologies.
Meanwhile, we can test the different performance indicators of different communication technologies and also evaluate the complex network communication system with multiple communication modes to support a basis selection for the typical communication solution which can meet various business needs. When the arrival of smart meter, collector of electromagnetic waves generated by the sensor network, which will produce instantaneous due to the need to consider the influence of sensor network of the equipment. Therefore, it is necessary to build the micro power wireless network as shown in Figure 12.

Sensor networks usually produce electromagnetic radiation generated by electrostatic discharge (ESD) and electrical fast transient (EFT) in the smart home, which could cause different harm for other equipment. Electrostatic discharge is about $5 \sim 200 \mathrm{MHz}$ frequency range, which can generate a strong radio frequency radiation. And the electrical fast transient burst can also produce very strong radiation; the induced voltage in electronic devices around can reach several hundred volts, which is far more than the voltage allowable value of the general electronic equipment. Smart home, smart socket, and other equipment often encounter unexpected voltage transients and surges, which causes the device semiconductor device (including diodes, transistors, thyristors, and integrated circuits) to be burned or to break down. According to statistics, about $75 \%$ of electronic equipment fails due to the transients and surges caused.

The concentrator and PLC module (or RS485 module) can exchange data with the intelligent meter. We usually adopt the narrowband power line carrier technology to collect the data from the concentrator and the intelligent meter as shown in Figure 13.

When the electromagnetic waves generated by wireless sensor networks reach the smart meter, collector, it will generate the transient induced current and induced voltage, 


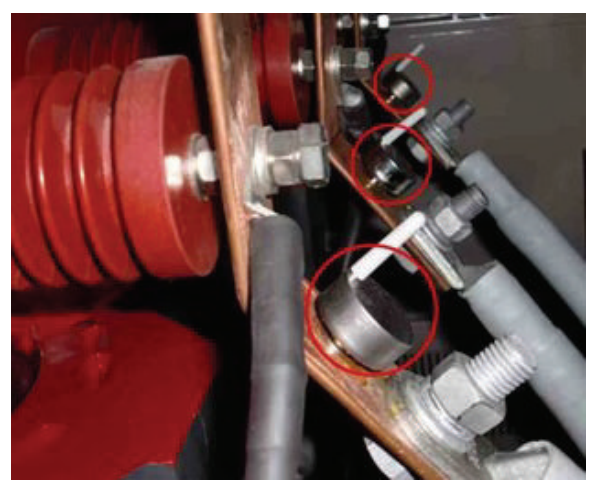

(a) Petersen coil outlet cable connector

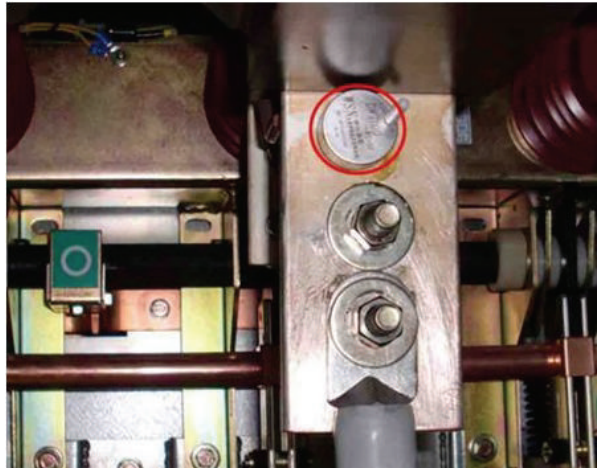

(b) Switchgear outlet cable connector

Figure 10: Sensors deployed in the real environment.

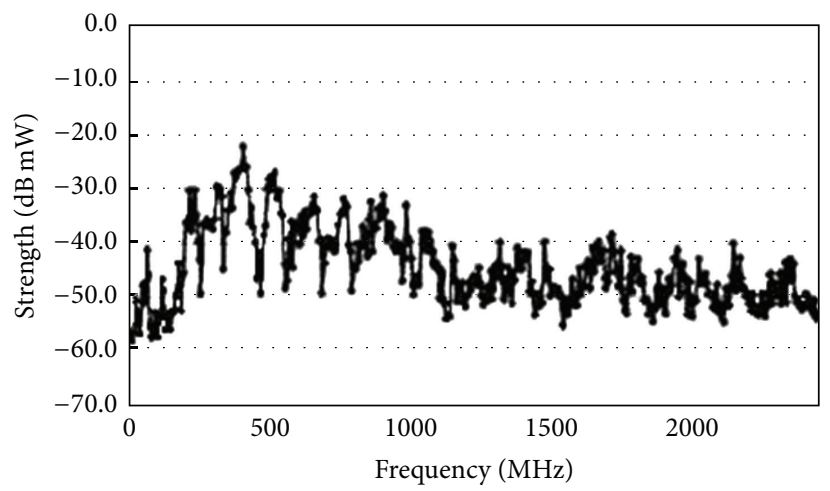

FIGURE 11: $\mathrm{SF}_{6}$ spectrum gap breakdown.

which impacts the performance parameters of electrical equipment. We analyze it from two aspects.

3.4. The Effects Induced Current. Usually, the meter can withstand the equivalent about $20 I_{\max }$ induced current (deviation: $+0 \%-10 \%$ ), and the time is normally less than $0.5 \mathrm{~s}$. When the induced current passes through the meter in a preset period of time, the collected information should not be changed to work correctly, and the deviation should not exceed the amount of change in the relevant provisions of the standard meter. The electromagnetic radiation from wireless sensor network node generally performs as a short period of several bursts, high pulse repetition frequency, and rise time. The pulse waveform is short; however the energy of a single pulse is small, which usually does not cause equipment failure, but causes the situation that equipment malfunctions often are visible. Therefore, it requires those smart meters, collectors, and other switches in the test of time to work correctly.

3.5. Effects Induced Voltage. Because the transient induced voltage will cause the meter and collector voltage drop and the current voltage accidentally fell more than $10 \%-15 \%$, thus it affected the normal operation of the meter and caused the malfunction of smart meters and missing collection information. Specified operating ranges of smart meters and collector typically are $0.9 \mathrm{Un}-1.1 \mathrm{Un}$, where Un represents the normal operating voltage meter. Response induced voltage generated by sensor network effective test to ensure that smart meters crash or information changes does not occur.

\section{Conclusion}

Smart grid adopts wildly various sensors to support lots of applications in all aspects, such as sensing work environment, monitoring production process, and realizing the automation control. However, due to the wireless and open communication, the electromagnetic phenomena in the communication and the electric network, the sensor network usually produces the mutual interference. Meanwhile, types of electrical equipment usually employ high pressure electromagnetic environment. In this paper, we introduce the application in smart grid and analyze the mutual influence between smart grid and sensor network. Therefore, sensing and communication device must be after equal parameter simulation environment under strict evaluation and verification can be put to use in actual production operation system. In this paper, we analyze the application of wireless sensor network in smart grid and propose the test method of the interaction between WSN and smart grid. With the development of application in smart grid, we will establish a more universal applicability testbed to increase the sensor test range in the future. 


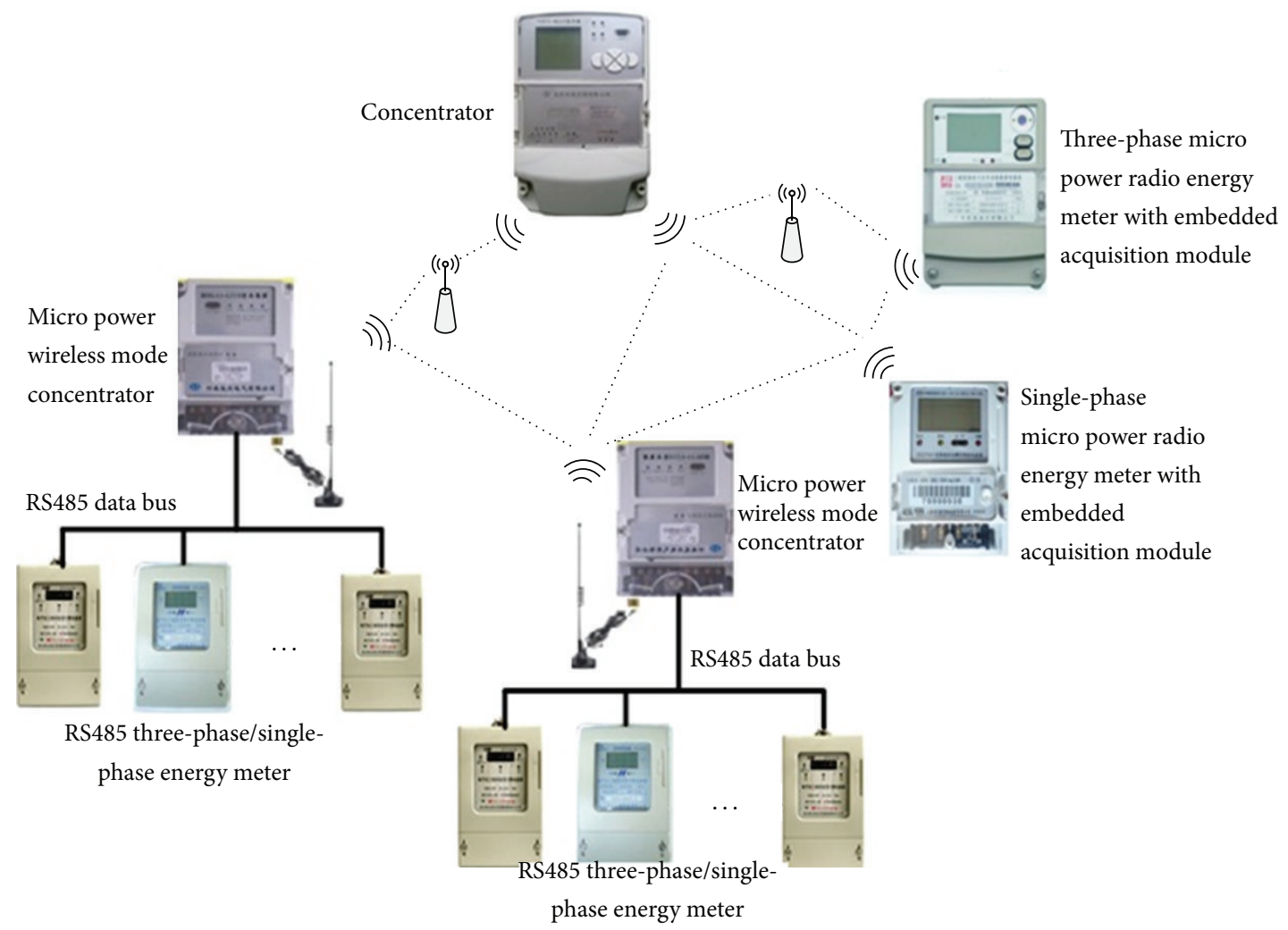

FIGURE 12: Micro power wireless networking.

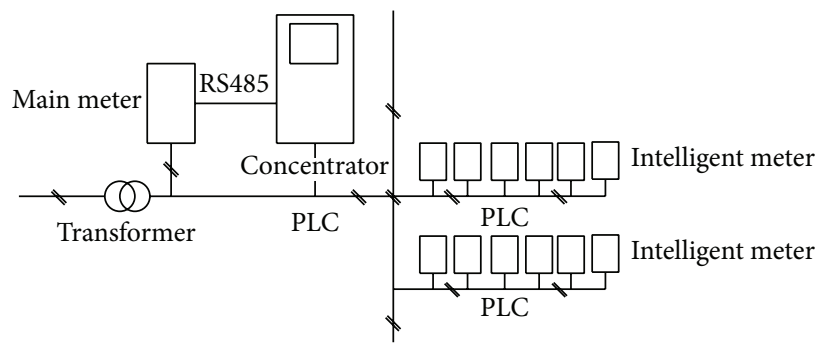

FIGURE 13: Concentrator and PLC model.

\section{Conflict of Interests}

The authors declare that there is no conflict of interests regarding the publication of this paper.

\section{References}

[1] V. C. Gungor, B. Lu, and G. P. Hancke, "Opportunities and challenges of wireless sensor networks in smart grid," IEEE Transactions on Industrial Electronics, vol. 57, no. 10, pp. 3557-3564, 2010.

[2] Y. Liu, "Wireless sensor network applications in smart grid: recent trends and challenges," International Journal of Distributed Sensor Networks, vol. 2012, Article ID 492819, 8 pages, 2012.

[3] Y. Zhang, X. Li, S. Zhang, and Y. Zhen, "Wireless sensor network in smart grid: applications and issue," in Proceedings of the IEEE World Congress on Information and Communication
Technologies (WICT '12), pp. 1204-1208, Trivandrum, India, October 2012.

[4] T. Gómez, C. Mateo, Á. Sánchez, P. Frías, and R. Cossent, "Reference network models: a computational tool for planning and designing large-scale smart electricity distribution grids," in High Performance Computing in Power and Energy Systems, Power Systems, pp. 247-279, Springer, Berlin, Germany, 2013.

[5] F. Li, W. Qiao, H. Sun et al., "Smart transmission grid: vision and framework," IEEE Transactions on Smart Grid, vol. 1, no. 2, pp. 168-177, 2010.

[6] X. Li, Q. Gong, and H. Qiao, “The application of IOT in power systems," Relay, no. 22, pp. 232-236, 2010.

[7] P. Rodriguez, A. V. Timbus, R. Teodorescu, M. Liserre, and F. Blaabjerg, "Flexible active power control of distributed power generation systems during grid faults," IEEE Transactions on Industrial Electronics, vol. 54, no. 5, pp. 2583-2592, 2007.

[8] Y. Yang, F. Lambert, and D. Divan, "A survey on technologies for implementing sensor networks for power delivery systems," 
in Proceedings of the Power Engineering Society General Meeting, pp. 1-8, IEEE, Tampa, Fla, USA, June 2007.

[9] V. C. Gungor, O. B. Akan, and I. F. Akyildiz, "A real-time and Reliable Transport (RT) ${ }^{2}$ protocol for wireless sensor and actor networks," The IEEE/ACM Transactions on Networking's, vol. 16, no. 2, pp. 359-370, 2008.

[10] Z. W. Liu and L. I. Rui, "Research and application of sensor identification normalization in smart grid," Telecommunications for Electric Power System, no. 12, pp. 90-94, 2012.

[11] J. Cao, J. Liu, Y. Zhang, X. Li, and L. Zeng, "Developing a power wireless private network based on TD-LTE technology for intelligent distribution networks," in Proceedings of the International Conference on Automatic Control and Artificial Intelligence (ACAI '12), pp. 890-893, Xiamen, China, March 2012.

[12] H. Zhang, A. Chen, M. Niyi, and J. Ding, "Research on the key technology of smart substation model configuration and check," in Proceedings of the International Conference on Advanced Power System Automation and Protection (APAP '11), pp. 291294, Beijing, China, October 2011.

[13] Y. T. Yin, M. Y. Yang, and Y. K. Zheng, "Overview of networked secondary system of intelligent substation and its on-line monitoring," Electrical Automation, vol. 36, no. 1, 2014.

[14] G. N. Ericsson, "Cyber security and power system communication-essential parts of a smart grid infrastructure," IEEE Transactions on Power Delivery, vol. 25, no. 3, pp. 1501-1507, 2010.

[15] K. S. Kim, H. Kim, T. W. Heo, Y. Doh, and J. A. Jun, "A samrt grid testbed using wireless sensor networks in a building," in Proceedings of the 5th International Conference on Sensor Technologies and Applications (SENSORCOMM '11), Saint-Laurentdu-Var, France, August 2011.

[16] L. Yan, Z. Zhang, and J. S. Yang, "Application of sensor in structure monitoring of large-span tunnel underpass highvoltage power transmission tower," Transducer and Microsystem Technologies, no. 4, pp. 151-154, 2015.

[17] C. F. M. Carobbi and M. Stecher, "The effect of the imperfect realization of the artificial mains network impedance on the reproducibility of conducted emission measurements," IEEE Transactions on Electromagnetic Compatibility, vol. 54, no. 5, pp. 986-997, 2012.

[18] K. K. Lehmann and D. Romanini, "The superposition principle and cavity ring-down spectroscopy," Journal of Chemical Physics, vol. 105, no. 23, pp. 10263-10277, 1996.

[19] A. Boulis, R. Berriman, S. Attar, and Y. Tselishchev, "A wireless sensor network test-bed for structural health monitoring of bridges," in Proceedings of the 36th Annual IEEE Conference on Local Computer Networks (LCN '11), pp. 1040-1043, IEEE, Bonn, Germany, October 2011.

[20] Y. Cai, G. Liu, L. Li, and H. Liu, "Design and test of nodes for farmland data acquisition based on wireless sensor network," Transactions of the Chinese Society of Agricultural Engineering, vol. 25, no. 4, pp. 176-178, 2009.

[21] J. W. Kuang and J. Y. Huang, "Design of distributed photovoltaic power station and application of the intelligent monitoring system," Mechanical \& Electrical Engineering Technology, no. 4, pp. 148-151, 2014.

[22] X.-X. Zhang, W.-T. Liu, J. Tang, and P. Xiao, "Study on PD detection in $\mathrm{SF}_{6}$ using multi-wall carbon nanotube films sensor," IEEE Transactions on Dielectrics \& Electrical Insulation, vol. 17, no. 3, pp. 833-838, 2010. 


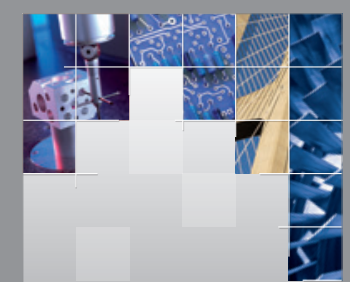

\section{Enfincering}
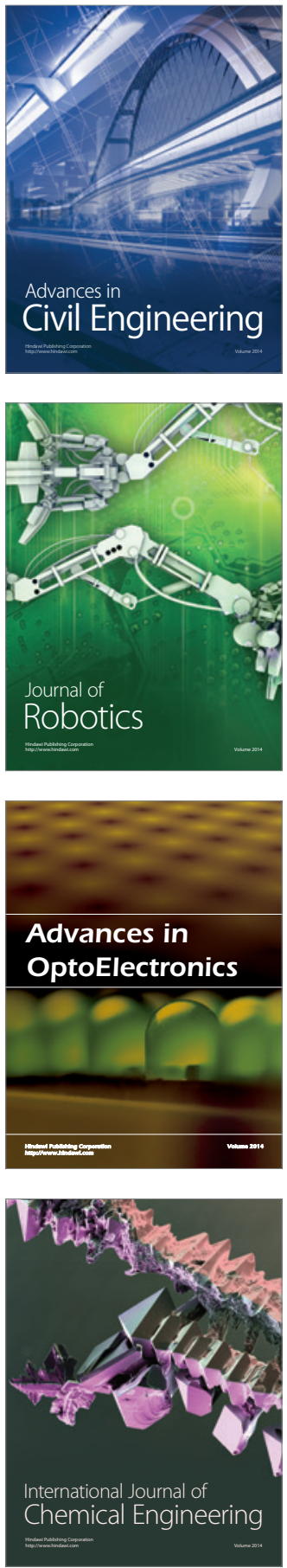

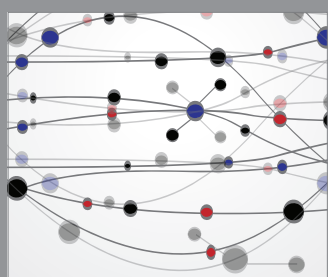

The Scientific World Journal

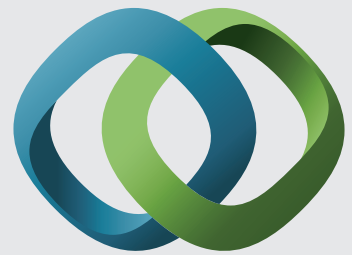

\section{Hindawi}

Submit your manuscripts at

http://www.hindawi.com
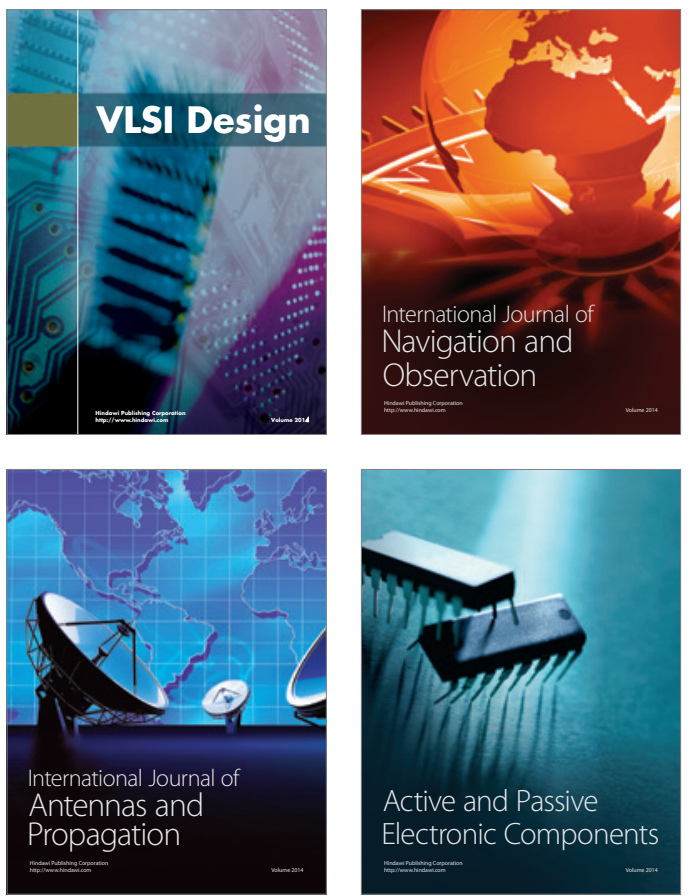
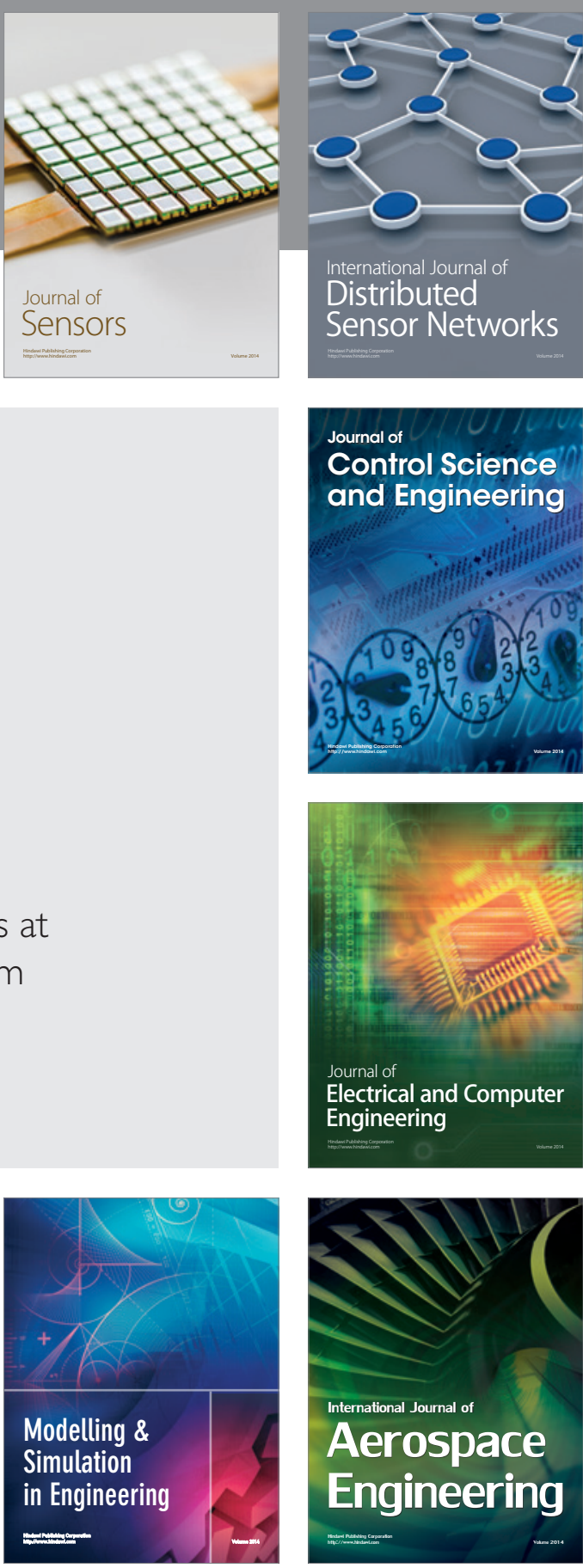

International Journal of

Distributed

Sensor Networks

Journal of

Control Science

and Engineering
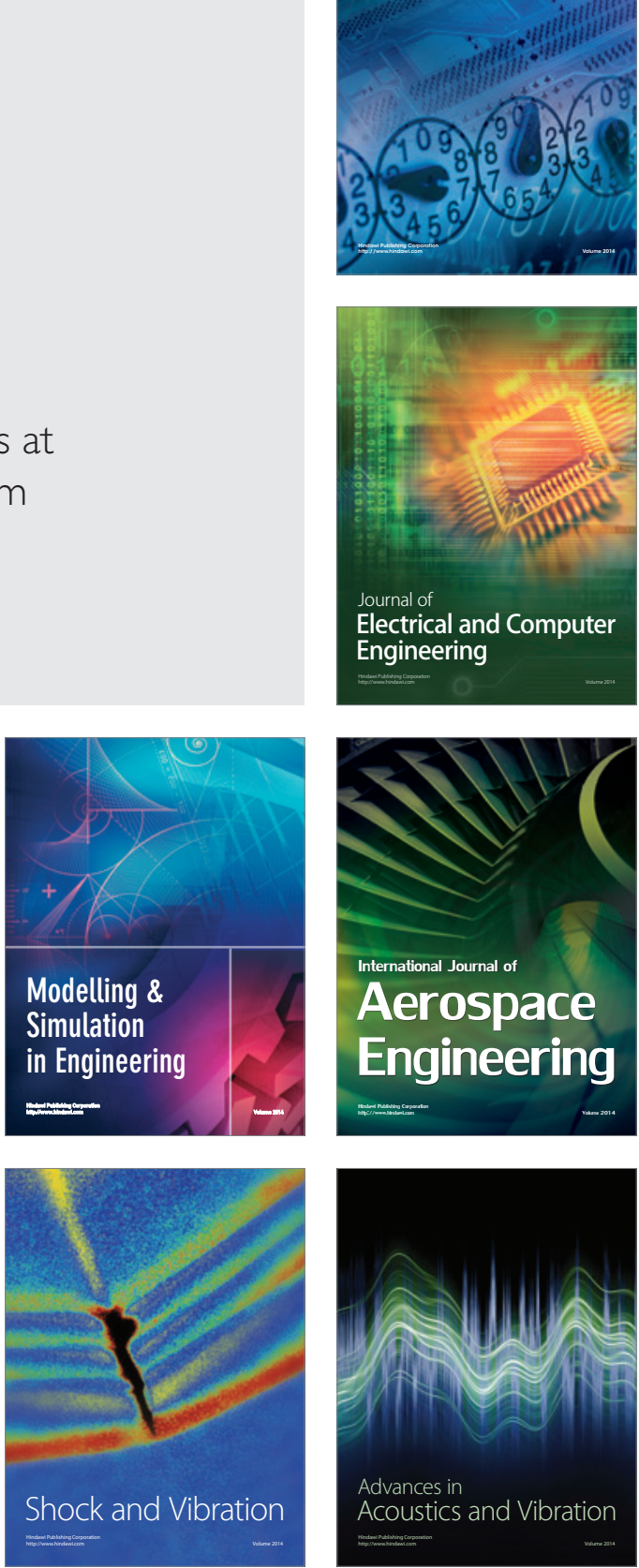